\title{
Fiscalización del IFE a partidos políticos nacionales
}

Alfredo Cristalinas*

\section{Sumario:}

I. Novedades de la reforma electoral en la fiscalización

II. Pendientes de la reforma electoral

III. Fiscalización sólida

* Director de la Unidad de Fiscalización del IFE.

D. R. (c) 2012. Universidad Nacional Autónoma de México-Instituto de Investigaciones Jurídicas. 
A 18 años de realizar la tarea de la fiscalización de los recursos de los partidos políticos en México, hoy en día reviste gran importancia, es uno de los temas fundamentales de la agenda electoral.

La reforma constitucional de 2007, si bien no supuso una variación sustancial en los procedimientos para el control y vigilancia del origen y uso de todos los recursos partidistas, definió al órgano del Instituto Federal Electoral (IFE) que tendría a su cargo la fiscalización de las finanzas de los partidos políticos nacionales.

En su tarea fiscalizadora, la Unidad de Fiscalización de los Recursos de los Partidos Políticos instrumenta procedimientos de revisión, verificación y auditoría, así como de investigación de los recursos de los sujetos obligados a la rendición de cuentas en materia electoral, que invariablemente se asocia a sus consecuencias, esto es: sanciones, que en la mayoría de los casos impactan en la economía de los partidos como es el caso de las multas y disminuciones de sus prerrogativas, así como amonestaciones públicas, cancelación de registro como candidatos y, en su extremo, la pérdida del registro como instituto político.

Los resultados de la fiscalización, permiten al Consejo General del IFE determinar el cumplimiento o la omisión a las reglas que rigen la obtención y el uso de los recursos.

\section{Novedades de la reforma electoral en la fiscalización}

Al implementar la reforma electoral 2007-2008, la Unidad de Fiscalización de los Recursos de los Partidos Políticos (UFRPP) asumió las atribuciones que anteriormente correspondían a la Comisión de Fiscalización y le fueron encomendadas otras más, que robustecieron el marco de la fiscalización, entre las cuales destacan:

\section{La creación de un órgano técnico}

La UFRPP tiene nivel jerárquico equivalente a una dirección ejecutiva del IFE, cuya finalidad consiste en lograr profesionalizar la función fiscalizadora y generar condiciones de imparcialidad, pues a juicio de los autores de la iniciativa, el diseño legal precedente ocasionaba "distorsiones" innecesarias en el trato de los consejeros integrantes de la 
Comisión de Fiscalización y los representantes de los partidos políticos ante el propio Consejo, además de que el largo tramo de desahogo de los procedimientos (secretario técnico-presidente de la Comisiónpresidente del Consejo-secretario ejecutivo) hacía lento y discontinuo el ejercicio de tal atribución.

\section{Autonomía de gestión}

El mandato constitucional otorga, al órgano técnico de supervisión de las finanzas de los partidos políticos, autonomía en su funcionamiento, busca procurar un desahogo táctico de las nuevas atribuciones conferidas, además de fortalecer los canales de comunicación y acción con la estructura desconcentrada del Instituto.

Si bien se no se trata de una autonomía extrapoder, la autonomía de relevancia constitucional ha valido para que, de la mano con la profesionalización, se fortalezca la autoridad fiscalizadora tutelando los principios de certeza, legalidad, imparcialidad, independencia y objetividad. Consecuentemente, se percibe una autoridad sensible, pero firme, objetiva y lo más importante, brinda confianza.

Como parte de la autonomía, el Reglamento Interior de la Unidad de Fiscalización establece que este órgano técnico está integrado por una dirección general y dos direcciones de área: la de auditoría, encargada de revisar los informes, realizar las visitas de campo, auditar las finanzas y elaborar el dictamen consolidado, y la de responsabilidades, que desahoga procedimientos oficiosos, de queja y los proyectos de resolución que la unidad de fiscalización presenta a aprobación del Consejo General.

A raíz de la reforma, la Unidad de Fiscalización en el ejercicio de su autonomía de gestión, ha implementado mecanismos de comprobación que le permiten avanzar en la generación de conciencia de riesgo en los sujetos obligados, promueve el cumplimiento voluntario y sanciona a quienes actúan fuera de la ley.

Al no contar con una estructura desconcentrada propia, la UFRPP se auxilia de las juntas ejecutivas locales y distritales las que apoyan su labor en la notificación de diversas determinaciones como solicitudes de información y confirmaciones a sujetos obligados y terceros relacionados; también auxilian en el monitoreo de medios impresos, propaganda móvil y fija y en la liquidación del otrora Partido Social 
Demócrata, en la concentración de los activos con el objeto de ponerlos a disposición del interventor.

\section{Franqueo de los secretos bancario, fiduciario y fiscal}

La inoponibilidad de los secretos bancario, fiduciario y fiscal en el ámbito de la fiscalización electoral, tuvo su justificación en la necesidad de que la Unidad de Fiscalización cumpla efectivamente con sus atribuciones, dotándola de los mecanismos legales que le permitieran ejercer sus labores de control y vigilancia sin los obstáculos afrontados en el pasado.

Constituye un precedente relevante para la fiscalización de los recursos que reciben los partidos, la resolución del Tribunal Electoral del Poder Judicial de la Federación relativa a las facultades del IFE para investigar el financiamiento ilícito de "Los Amigos de Fox".

El acceso a la información relativa a las operaciones bancarias o situación fiscal de los recursos de los partidos políticos nacionales, ha fortalecido la función de fiscalización y rendición de cuentas, proporcionando a la autoridad mayores elementos para desarrollar sus facultades para investigar hechos o conductas ilegales, dentro de un marco legal que garantiza la reserva de la información financiera y garantiza los derechos de los particulares.

Lo anterior ha contribuido a la transparencia, seguridad y legalidad en las operaciones ordinarias de los institutos políticos y en los procesos electorales; sin embargo. no constituye la garantía de eliminar el ingreso de recursos de procedencia ilícita en las contiendas electorales, pues atiende principalmente a operaciones que se suscitan en el sistema financiero, sin que esto signifique bajar la guardia, pues el uso exhaustivo de esta atribución tiene sus recompensas.

Durante la revisión de los Informes de Precampaña del proceso electoral federal 2008-2009, se realizaron 175 solicitudes de información de los partidos y los terceros con los que tuvieron operaciones, al Servicio de Administración Tributaria (SAT); se analizaron 700 cuentas bancarias con la Comisión Nacional Bancaria y de Valores (CNBV), para determinar el origen de las aportaciones de 500 individuos (simpatizantes, militantes y candidatos), y por último, a la Unidad de Inteligencia Financiera (UIF) de la Secretaría de Hacienda y Crédito Público, se remitieron listados con 4857 registros de precan- 
didatos para analizar operaciones relevantes o inusuales. El resultado de éste análisis dio origen a una vista a la Auditoría Superior del Estado de Michoacán respecto de las operaciones de un candidato a diputado federal por esa entidad que además resultó ganador en 2009.

En la revisión de los informes de campaña, se solicitaron cuentas bancarias de 240 candidatos de todos los partidos políticos; se giraron 175 oficios de solicitud de información al SAT respecto de operaciones que involucran a personas físicas y personas morales.

El manejo cuidadoso y confidencial de este tipo de información permitió concluir los trabajos de fiscalización sin sucesos que pudieran no sólo poner en riesgo el resultado de la revisión, sino la propia elección y vulnerar la confianza de los partidos políticos y de la sociedad en general.

Asimismo, durante la revisión a los rubros de gastos por actividades específicas y $2 \%$ para la capacitación, promoción y desarrollo del liderazgo político de la mujer, en el periodo comprendido entre el 1o. de enero de 2010 y el 30 de junio del mismo año, se giraron 47 solicitudes de información al SAT. Esto permitió detectar inconsistencias entre las actividades reportadas por los institutos políticos y las manifestadas por la autoridad fiscal.

Durante el procedimiento de revisión del Informe Anual del ejercicio 2010, se remitieron 42 solicitudes de información a la CNBV, y 30 al SAT.

\section{Convenios con otras autoridades}

La inoponibilidad de los secretos bancario, fiduciario y fiscal a la Unidad de Fiscalización, ha permitido establecer un nuevo eje de coordinación con otras autoridades para el ejercicio efectivo de las facultades que tiene encomendadas.

A continuación se citan los rasgos relevantes de la coordinación con cada autoridad:

Servicio de Administración Tributaria. Provee información de las declaraciones anuales, pagos mensuales provisionales y definitivos de impuestos, con la finalidad de valorar la capacidad económica de los sujetos obligados y de terceros relacionados con los mismos.

Además de la información fiscal, provee información de terceros relacionados con los partidos políticos relativa a la actividad prepon- 
derante; nombre de socios, accionistas y representa legal; domicilio fiscal actual e histórico de domicilios o bien domicilios de sucursales; entre otros datos que apoyan al análisis contextual en el que un partido realiza sus operaciones en carácter de cliente.

Comisión Nacional Bancaria y de Valores. Se obtiene información del flujo de efectivo (depósitos y retiros) dentro de las instituciones que integran el sistema financiero, con el propósito de conocer el origen y destino de los dineros que emplean los partidos políticos, precandidatos y candidatos.

Unidad de Inteligencia Financiera (UIF). El intercambio de información asociada a personas políticamente expuestas propicia el inicio de investigaciones en aquellos casos en que existen operaciones relevantes, preocupantes o inusuales reportadas por la UIF lo que permite diseñar procedimientos y ampliar alcances de revisión.

Fiscalía Especializada para la Atención de Delitos Electorales. Sustanciación recíproca de expedientes asociados al financiamiento $\mathrm{y}$ gasto de partidos políticos, precandidatos y candidatos.

\section{Conductas detectadas en la revisión de informes}

Un golpe de timón en el paradigma de la función, fue el transitar de la determinación de actos y omisiones para la detección de conductas de evasión. La trascendencia de este cambio impacta directamente la cultura del cumplimiento, pues la evidencia y determinación de conductas tiene que ver precisamente con la adminiculación de acciones u omisiones para sacar alguna ventaja, dándole vuelta a la ley.

Para ilustrar con claridad lo anterior, diremos que la Unidad realizó seguimiento de flujos de efectivo durante la revisión del Informe Anual correspondiente al ejercicio 2010, detectando las conductas siguientes:

La subdeclaración de ingresos, cuyo propósito principal, para el caso de simpatizantes y militantes, es evitar el rebase de topes en las aportaciones, en tanto que los ingresos autogenerados y por rendimientos buscan tener recursos disponibles para erogaciones que no serán reportadas.

Ingresos no registrados, se detectaron ingresos no reportados por la cantidad de $\$ 165815.94$. El propósito de esta conducta es obtener recursos para erogaciones que no serán reportadas, o bien ocultar el 
origen de los mismos cuando provienen de fuentes no autorizadas por la ley.

Los ingresos en especie no registrados, se identifican a través de procedimientos orientados a la detección de erogaciones realizadas por terceros con proveedores, cuyos beneficios recibe el partido político. También puede ocultar el financiamiento de fuentes no autorizadas por la ley.

El financiamiento proveniente de fuentes ilícitas, se detectaron ingresos de fuentes no permitidas por un monto de $\$ 82070.49$, por lo cual, independientemente de las sanciones procedentes en materia electoral, se ordenó dar vista a las autoridades competentes para que, en el ámbito de sus respectivas facultades, determinen lo que en derecho proceda.

La subdeclaración de gastos, tiene como objetivo impedir el rebase de topes de gastos de campaña, lo que genera inequidad en la contienda.

Los gastos no reportados, se detectaron gastos no reportados por un monto de $\$ 165815.94$. La conducta de los institutos políticos tienen como objetivo impedir el rebase de topes de gastos de campaña, lo que genera inequidad en la contienda.

La simulación de operaciones, tienen como objetivo disponer de efectivo para la realización de actividades que propician inequidad en la contienda y que además no son reportadas.

En el marco de la revisión de los Informes de Campaña de 2009, se determinaron 66 casos de simulación que involucran 1.8 millones de pesos, mediante 300 solicitudes de información dirigidas a la CNBV.

\section{La coordinación entre el IFE y las autoridades electorales locales en materia de fiscalización de los partidos}

La ley estableció un esquema de centralización en el trámite de las solicitudes de información bancaria, fiduciaria o fiscal, como eje articulador de las tareas de coordinación entre las autoridades electorales federal y de las entidades federativas, a efecto de superar el obstáculo que constituye el ámbito competencial de dichas autoridades para la fiscalización de los recursos de los partidos políticos nacionales, en el efectivo control y supervisión de los ingresos y gastos de dichos institutos políticos. 
A la fecha, las solicitudes de intervención dirigidas por las autoridades electorales locales a la Unidad de Fiscalización, se han constituido en un mecanismo de coordinación en las labores de control y vigilancia de los recursos partidistas, pues implica el flujo de los soportes documentales respectivos y, consecuentemente, el conocimiento de la información que posea cada una de las instancias competentes.

El Instituto Federal Electoral ha suscrito 31 convenios de Coordinación para el apoyo y colaboración en el intercambio de información sobre el origen, monto y destino de los recursos de los partidos políticos, con igual número de entidades federativas, siendo Nayarit el único estado con el cual no se ha firmado el referido instrumento.

\section{Requerimientos de información a personas físicas y morales sobre operaciones realizadas con los partidos políticos nacionales}

La ley confirió facultad a la autoridad para requerir de las personas, físicas o morales, públicas o privadas, en relación con las operaciones que realicen con partidos políticos, la información necesaria para el cumplimiento de sus tareas, respetando en todo momento las garantías del requerido.

A raíz de la reforma, la Unidad de Fiscalización ha requerido información y documentación soporte a los proveedores y prestadores de servicios, con el fin de corroborar las operaciones que reportan los partidos políticos durante la revisión de sus informes de precampaña, campaña y de informe anual.

Durante la revisión a los rubros de gastos por actividades específicas y $2 \%$ para la capacitación, promoción y desarrollo del liderazgo político de la mujer, en el periodo comprendido entre el 1o. de enero de 2010 y el 30 de junio del mismo año, se realizaron 47 requerimientos de información.

En el marco de la revisión del Informe Anual correspondiente al ejercicio 2010, se realizaron 1340 confirmaciones de operaciones con terceros, de los cuales 915 eran personas físicas, y 425 personas morales, determinándose de las respuestas negativas un monto involucrado de $\$ 1974563.36$. 
Esta facultad ha permitido detectar inconsistencias en la rendición de cuentas que realizan los institutos políticos, otorgándoles la garantía de audiencia para que manifiesten lo que a su derecho conviene.

Sin embargo, el hecho que la Unidad de Fiscalización no cuente con facultades para realizar compulsas personales o visitas domiciliarias, limita el ejercicio pleno de la revisión, y con ello la capacidad de obtener evidencia suficiente por parte de los terceros involucrados en las operaciones. ${ }^{1}$

\section{Revisión de Informes de ingresos y gastos}

La recepción y revisión integral de los diversos informes de ingresos y gastos que deben presentar los partidos políticos nacionales, las agrupaciones políticas nacionales, las organizaciones de ciudadanos que participan en un proceso electoral como observadores electorales y las organizaciones políticas que han manifestado su intención de obtener su registro como partido político nacional.

Durante el proceso electoral federal 2008-2009, los partidos políticos nacionales y coaliciones presentaron un total de 2028 Informes de Campaña, en los cuales se detectaron 416 irregularidades, 399 de forma y 17 de fondo.

Se ordenaron 21 vistas a autoridades y el inicio de 80 procedimientos oficiosos, el monto total de las sanciones impuestas a los institutos políticos ascendió a la cantidad de \$32 707665.39 , como se ilustra:

1 El 1o. de diciembre de 2010, la Sala Superior del TEPJF resolvió que la UFRPP del IFE no cuenta con facultades para practicar visitas domiciliarias o compulsas personales a las personas físicas o morales, públicas o privadas en relación con las operaciones que realicen con partidos políticos. 
Informes de campaña

\begin{tabular}{|c|c|c|c|c|}
\hline \multirow{2}{*}{$\begin{array}{l}\text { Partido } \\
\text { Político/ } \\
\text { Coalición }\end{array}$} & \multicolumn{2}{|c|}{ IMPORTES } & \multirow{2}{*}{$\begin{array}{l}\text { Monto total de } \\
\text { sanción }\end{array}$} & \multirow{2}{*}{$\begin{array}{c}\text { Porcentaje } \\
\text { con respecto } \\
\text { al ingreso }\end{array}$} \\
\hline & INGRESOS & EGRESOS & & \\
\hline $\begin{array}{l}\text { Partido Acción } \\
\text { Nacional }\end{array}$ & $\$ 219890307.74$ & $\$ 220288775.64$ & $\$ 3371284.34$ & $1.53 \%$ \\
\hline $\begin{array}{c}\text { Partido } \\
\text { Revolucionario } \\
\text { Institucional }\end{array}$ & $\$ 143221294.34$ & $\$ 142022919.20$ & $\$ 5899992.44$ & $4.12 \%$ \\
\hline $\begin{array}{l}\text { Partido de la } \\
\text { Revolución } \\
\text { Democrática }\end{array}$ & $\$ 191178635.74$ & $\$ 190583881.77$ & $\$ 9447195.42$ & $4.94 \%$ \\
\hline $\begin{array}{l}\text { Partido Verde } \\
\text { Ecologista de } \\
\text { México }\end{array}$ & $\$ 121114913.61$ & $\$ 121114913.61$ & $\$ 576888.87$ & $0.48 \%$ \\
\hline $\begin{array}{l}\text { Partido Nueva } \\
\text { Alianza }\end{array}$ & $\$ 45700789.07$ & $\$ 45385479.78$ & $\$ 277014.00$ & $0.61 \%$ \\
\hline $\begin{array}{l}\text { Coalición } \\
\text { Primero } \\
\text { México }\end{array}$ & $\$ 35703842.08$ & $\$ 35564894.67$ & $\$ 11445634.36$ & $32.06 \%$ \\
\hline $\begin{array}{l}\text { Coalición } \\
\text { Salvemos a } \\
\text { México }\end{array}$ & $\$ 167759014.41$ & $\$ 156956190.60$ & $\$ 1689655.91$ & $1.01 \%$ \\
\hline Total & $\$ 924568796.99$ & $\$ 911917055.27$ & $\$ 32707665.34$ & $4 \%$ \\
\hline
\end{tabular}

Se acreditaron 64 casos de rebases de tope de gastos de campaña, que fueron sancionados por un total de $\$ 7280347.09$.

Por otra parte, en el marco de la revisión a los Informes Anuales de los partidos políticos nacionales correspondientes al ejercicio 2010, se determinó un monto involucrado de las observaciones sancionables por la cantidad total de $\$ 159533350.00$, de los cuales $\$ 9204152.00$ corresponden a irregularidades de forma y $\$ 67491830.00$ de fondo.

Las irregularidades detectadas por la Unidad de Fiscalización fueron sancionadas por el Consejo General del IFE por un monto total de \$66539 084.13, como a continuación se ilustra: 


\begin{tabular}{|c|c|c|c|}
\hline \multicolumn{3}{|c|}{ Sanción } \\
\hline Partido Político & Forma & Fondo & Total \\
\hline $\begin{array}{c}\text { Partido Acción } \\
\text { Nacional }\end{array}$ & $\$ 750772.60$ & $\$ 9010476.25$ & $\$ 9761248.85$ \\
\hline $\begin{array}{c}\text { Partido } \\
\text { Revolucionario } \\
\text { Institucional }\end{array}$ & $\$ 2066658.95$ & $\$ 24673606.25$ & $\$ 26740265.20$ \\
\hline $\begin{array}{c}\text { Partido de la } \\
\text { Revolución } \\
\text { Democrática }\end{array}$ & $\$ 1451371.30$ & $\$ 13189258.60$ & $\$ 14640629.90$ \\
\hline $\begin{array}{c}\text { Partido del } \\
\text { Trabajo }\end{array}$ & $\$ 791151.15$ & $\$ 4490751.85$ & $\$ 5281903.00$ \\
\hline $\begin{array}{c}\text { Partido Verde } \\
\text { Ecologista de } \\
\text { México }\end{array}$ & $\$ 303412.00$ & $\$ 1172725.88$ & $\$ 1476137.88$ \\
\hline $\begin{array}{c}\text { Partido } \\
\text { Convergencia }\end{array}$ & $\$ 332446.20$ & $\$ 6036309.00$ & $\$ 6368755.20$ \\
\hline $\begin{array}{c}\text { Partido Nueva } \\
\text { Alianza }\end{array}$ & $\$ 1582507.35$ & $\$ 687636.75$ & $\$ 2270144.10$ \\
\hline Total & $\$ 7278319.55$ & $\$ 59260764.58$ & $\$ 66539084.13$ \\
\hline
\end{tabular}

\section{Fiscalización de precampañas}

La regulación de los informes de precampaña fue la respuesta a las exigencias de transparentar los recursos con los cuales los aspirantes a obtener alguna candidatura, despliegan actos para publicitar su persona, perfil, trayectoria y méritos, así como para homogeneizar y fortalecer los procesos internos de selección de candidatos al seno de los partidos políticos.

Con la reforma se amplía el espectro de los sujetos responsables de la rendición, pues al precandidato corresponde la elaboración del informe de ingresos y gastos, deberá entregarlo al órgano interno del partido 
competente a más tardar dentro de los 7 días siguientes al de la jornada comicial interna o celebración de la asamblea respectiva, siendo la tarea del partido recibir y entregar a la Unidad de Fiscalización dichos informes.

El reto impuesto a la autoridad fiscalizadora fue instaurar los procedimientos ordinarios, y en su caso expeditos de revisión de los citados informes, lo cual abona a la fiscalización que debe efectuarse, toda vez que la falta de presentación por parte del precandidato del informe de precampaña, trae como consecuencia que el ciudadano de que se trate no pueda "ser registrado legalmente como candidato", si es que obtuvo la mayoría de votos en la contienda interna o en la asamblea partidista, asimismo, los precandidatos que rebasen el tope de gastos de precampaña que les corresponda, serán sancionados con la cancelación de su registro o, en su caso, con la pérdida de la candidatura que hayan obtenido.

El Proceso Electoral Federal 2008-2009, constituyó la primera ocasión en que los ingresos y gastos de los precandidatos postulados por los partidos políticos nacionales serían fiscalizados. La Unidad recibió 4887 informes de precampaña.

El Consejo General del IFE determinó el inicio de procedimientos expeditos ${ }^{2}$ de revisión respecto de 1964 informes de precampaña, determinando irregularidades con un monto involucrado de $\$ 1535494.72$, mismas que fueron objeto de sanción por un monto total de $\$ 1507274.00 .^{3}$

Asimismo, se revisaron los restantes 2923 informes bajo el procedimiento ordinario, detectándose 366 irregularidades, de las cuales únicamente 124 no fueron subsanadas y originaron sanciones ${ }^{4}$ por un monto total de $\$ 1125927.12$, y se ordenó el inicio de dos procedimientos oficiosos.

\section{Informes preliminares de campaña}

Con la finalidad de fortalecer los mecanismos de control de los recursos, se estableció que la Unidad de Fiscalización hará públicos en el

\footnotetext{
2 Acuerdo CG153/2009, aprobado en sesión extraordinaria del 20 de abril de 2009.

3 Acuerdo CG186/2009, aprobado en sesión extraordinaria del Consejo General del IFE el 15 de mayo de 2009.

4 Acuerdo del Consejo General CG496/2009.
} 
portal de Internet del IFE, los informes preliminares de campaña que a raíz de la reforma deben presentar los partidos políticos.

Derivado del Proceso Electoral Federal 2008-2009, el órgano técnico coadyuvó a la emisión del voto informado por parte del electorado al dar cumplimiento a la tarea encomendada.

\section{Verificaciones a precampañas y campañas electorales}

El efectivo control y vigilancia de los recursos con que cuenten los partidos políticos durante los procesos electorales, mediante la detección de operaciones vinculadas con el gasto ejercido para obtener la preferencia del electorado, motivó las facultades conferidas a la Unidad de Fiscalización para ordenar visitas de verificación.

Durante el pasado proceso electoral federal 2008-2009, la Unidad de Fiscalización ordenó la verificación de 298 fórmulas en campaña, en 44 distritos electorales de las 32 entidades del país, que fueron seleccionados bajo criterios técnicos.

Las visitas se realizaron durante el periodo de campaña, incluso en los cierres de éstas. Se identificaron diversos gastos de propaganda y publicidad, siendo los más relevantes, los relativos al uso de vehículos, casas de campaña no reportadas y gastos para cierres de campaña, en donde se incluían grupos musicales, cantantes y grupos de animadores, entre otros.

La práctica de visitas de verificación permite a la Unidad de Fiscalización allegarse de los insumos necesarios para cotejar, en primer término, los gastos reportados por los precandidatos o candidatos de los partidos políticos o coaliciones en sus Informes de Precampaña y Campaña. Los datos obtenidos de la verificación correspondiente, y en consecuencia, determinar si se cumplieron o no los requisitos reglamentarios para el ejercicio del gasto y su comprobación.

El Reglamento de Fiscalización, aprobado por el Consejo General el pasado 4 de julio, establece las reglas para realizar las visitas de verificación, lo cual contribuye a robustecer el marco normativo que sustenta la actuación del órgano técnico. 


\section{Auditorías a las finanzas de los partidos políticos}

La reforma electoral confirió a la Unidad de fiscalización facultades para ordenar la práctica de auditorías, directamente o a través de terceros, a las finanzas de los partidos políticos.

En ejercicio de sus atribuciones, la autoridad ordenó la revisión a los rubros de gastos por actividades específicas y $2 \%$ para la capacitación, promoción y desarrollo del liderazgo político de la mujer, que los partidos políticos nacionales reportaron durante el periodo comprendido entre el 1o. de enero de 2010 y el 30 de junio del mismo año.

El universo de revisión comprendió 227 operaciones efectuadas con proveedores y prestadores de servicios, por un valor total de $\$ 52821527.05$. Las muestras a revisar fueron de 47 operaciones, por un monto de $\$ 46602057.64$, seleccionadas aplicando el principio de "pareto" (regla 80-20); lo cual representó un $88.23 \%$ del alcance de la revisión.

Derivado de la práctica de esta auditoría, se detectó que los partidos políticos no administran sus programas a partir de un plan operativo anual o equivalente que les permita programar, medir y controlar, durante el ejercicio, los recursos destinados para actividades específicas y el liderazgo político de la mujer.

\section{Facultades reglamentarias}

La ley confirió facultades a la Unidad de Fiscalización para emitir normas generales respecto de los ingresos y egresos de los partidos políticos, así como para ser responsable de los procedimientos de liquidación.

El Consejo General del IFE aprobó el 4 de julio de 2011, los ordenamientos que constituyen la estructura normativa de las funciones de la Unidad de Fiscalización, a saber: el Reglamento de Fiscalización, el Reglamento de Procedimientos en Materia de Fiscalización y el Reglamento para la Liquidación y Destino de los Bienes de los Partidos Políticos Nacionales.

Al contar con una reglamentación sólida, la actuación del órgano técnico brindará mayor certeza y seguridad jurídica a los sujetos obligados a rendir cuentas en materia electoral. 


\section{Procedimientos administrativos de quejas y oficiosos en materia de origen y aplicación de recursos}

El ejercicio eficaz y oportuno de las atribuciones conferidas a la Unidad de Fiscalización, ha logrado abatir el rezago que se tenía desde 2004, mediante la elaboración de los Proyectos de Resolución derivados de las quejas y de los procedimientos oficiosos interpuestos en contra de diversos partidos políticos nacionales.

El Consejo General del IFE ha aprobado 396 resoluciones en esta materia, a partir de que la Unidad de Fiscalización de los Recursos de los Partidos Políticos tiene a su cargo la sustanciación de los procedimientos relacionados con el origen, destino y monto de los recursos otorgados a los institutos políticos.

Durante 2008, se iniciaron 55 procedimientos en materia de fiscalización, y en 2009, la Unidad de Fiscalización formó diversos expedientes relacionados con 106 procedimientos, mismos que han quedado concluidos.

A la fecha, la Unidad de Fiscalización cuenta con 10 procedimientos en sustanciación, de los cuales existe una queja, y 9 procedimientos oficiosos.

Lo anterior refleja el ejercicio exhaustivo de la actividad investigadora de la Unidad, a la luz de los principios de certeza, legalidad, independencia, imparcialidad y objetividad, y la colaboración de los órganos del IFE y otras autoridades.

\section{Los procedimientos de liquidación de los partidos políticos que pierdan su registro}

El 21 de agosto de 2009, el Partido Socialdemócrata perdió su registro como partido político nacional por no haber obtenido, por lo menos, el 2\% de la votación emitida en la elección federal ordinaria para diputados por los principios de mayoría relativa y representación proporcional, celebrada el 5 de julio de $2009 .{ }^{5}$

La Unidad de Fiscalización ha llevado a cabo el procedimiento de liquidación de los bienes y recursos del otrora Partido Socialdemó-

5 Mediante Resolución JGE76/2009, la Junta General Ejecutiva del IFE, emitió la "Declaratoria de Pérdida de Registro". 
crata, designando al interventor, una vez realizada la insaculación correspondiente. ${ }^{6}$

La Unidad de Fiscalización, como resultado de su revisión, emitió dictamen y proyectos de resolución relativos a los Informes de Campaña correspondientes al Proceso Electoral Federal 2008-2009, y al Informe Anual del otrora Partido Socialdemócrata, correspondiente al periodo del 1o. de enero de 2009 al 23 de septiembre de 2009, con cifras dictaminadas a esa fecha, los cuales fueron aprobados por el Consejo General del Instituto Federal Electoral, y quedaron firmes al no ser objeto de impugnación.

\section{Pendientes de la reforma electoral}

Existe una brecha entre el resultado de la fiscalización y las expectativas de la ciudadanía ante una reforma en la que se otorgaron mayores facultades para realizar esta tarea.

Las preguntas recurrentes de diferentes sectores de la sociedad han sido: ¿si se aplica dinero del narcotráfico o del crimen organizado en las campañas electorales?, ¿se coacciona el voto a través de la entrega de dinero o bienes que entrega el gobierno en el poder?, ¿se rebasaron los topes de campaña?

Respecto a la influencia del dinero del narcotráfico o del crimen organizado en las campañas, en su labor, la Unidad no ha detectado indicios de la participación del crimen organizado en las contiendas.

A raíz de la reforma electoral, el órgano fiscalizador ha ejercido de manera eficaz las facultades conferidas, sin embargo debe precisarse la diferencia entre la función de revisar, controlar y vigilar el origen y la aplicación de los recursos, así como la de investigar conductas delictivas.

La facultad de reprimir conductas consideradas ilícitas, es connatural a la organización del Estado. Al efecto, se han establecido dos regímenes sancionadores distintos: uno jurisdiccional y otro administrativo.

6 Mediante acuerdo CG414/2009, el Consejo General del Instituto IFE aprobó la creación del grupo de trabajo que ha dado seguimiento al procedimiento de liquidación. 
La división tienen su razón de ser en la naturaleza de los ilícitos que se pretenden sancionar y reprimir, pues el derecho penal tutela bienes jurídicos que el legislador ha considerado de mayor trascendencia e importancia por constituir una agresión directa contra los valores de mayor envergadura del individuo y del Estado que son fundamentales para su existencia; en tanto que con la tipificación y sanción de las infracciones administrativas se propende a la tutela de intereses generados en el ámbito social, y tienen por finalidad hacer posible que la autoridad administrativa lleve a cabo su función.

La rendición de cuentas y las facultades de fiscalización, se fortalecen con un régimen de sanciones por el incumplimiento de las obligaciones en materia de origen y destino de los recursos, y los procedimientos para su imposición, mismos que se encuentran regulados en el Código Federal de Instituciones y Procedimientos Electorales.

En otra vertiente, el Código Penal, en el título vigesimocuarto denominado "De los Delitos Electorales y en Materia de Registro Nacional de Ciudadanos”, regula la actuación de los funcionarios partidistas o candidatos que, obtengan y utilicen, a sabiendas y en su calidad de candidatos, fondos provenientes de actividades ilícitas para su campaña electoral. Conducta que resulta competencia de la Fiscalía Especializada en Delitos Electorales (FEPADE).

El Código Penal tipifica las conductas que serán consideradas como delitos en materia electoral, razón por la cual las anomalías detectadas el día de la jornada electoral deberán ser investigadas por la FEPADE y no por la Unidad de Fiscalización.

\section{Fiscalización sólida}

Las nuevas facultades y atribuciones en materia de fiscalización han constituido uno de los cambios más importantes del sistema electoral mexicano.

La articulación de los instrumentos de control y los medios de investigación, han permitido la especialización de cada uno de los ámbitos que integran la tarea encomendada, obteniendo una fiscalización más técnica y eficiente. La transición de una fiscalización reactiva a una fiscalización preventiva y proactiva, con mayor vigilancia de los 
recursos de los partidos políticos, lo cual coadyuva a la equidad entre los institutos políticos, la legalidad y la credibilidad.

La autoridad cumple con el principio de exhaustividad en su función, pero al mismo tiempo busca sensibilizar a los partidos en la responsabilidad que implica gozar de prerrogativas.

La fiscalización no tiene como fin la práctica de auditorías o la imposición de sanciones económicas. La fiscalización tiene por objeto lograr conciencia de riesgo en los sujetos obligados respecto del incumplimiento de sus obligaciones en materia de financiamiento y gasto para promover el cumplimiento voluntario.

El efecto deseado es inhibir conductas fuera de los cauces legales de los sujetos obligados, procurando que sus actividades se apeguen a los principios del Estado democrático y así cumplir la demanda de la sociedad de una rendición de cuentas clara y verdadera. 